Pre-publication manuscript. Article accepted for Popular Music (2017 issue). Do not quote before publication.

\title{
Dark timbre: The aesthetics of tone colour in goth music Isabella van Elferen
}

\begin{abstract}
Timbre is a key aspect of musical practice and aesthetics. Artists use instrumentation, vocal technique, and production technology to create precise tone colours; listeners are able to identify genres, artists, and connotations through timbre. But critical assessment of its ephemeral musical agency is scarce. This article develops a theory of timbre. Goth music, which privileges tone colour in production, performance, and aesthetic, is a case in point for the ungraspable agency of this musical parameter. Timbral analyses of two goth tracks, Veil of Light's 'Cold Skin' and Sopor Aeternus and the Ensemble of Shadows's 'Dreamland', will assess tone colour's relation to identity and difference (Walser), signification and corporeality (Barthes, Ihde), and the surplus of meaning and embodiment (Dolar). The article will argue that timbral aesthetics are characterised by the paradox of present absence: it indicates corporeality and meaning but simultaneously exceeds both. Tangible but also disembodied, immersive but also meaningless, it is no wonder that goth exploits timbre's dark agency.
\end{abstract}

\section{The darkness of musical difference: goth timbres}

According to legend goth originated in the Batcave club in Soho, London, which existed in the brief period between 1982 and 1985. Hollow-voiced and black-haired, the bands that performed there chanted gloomy lyrics of decay and Thatcherite emptiness over foregrounded bass lines. Their audiences revelled in this musically expressed misery and dressed in spectacularly Gothic ways. The club as well as the artists performing there -- among whom Bauhaus, Siouxsie and the Banshees, The Cure, and Alien Sex Fiend -- have become canonized as ur-Goth.

Since goth's early years in the Batcave the subculture's musical style has developed in a great variety of directions. The Batcave's oldschool style, which combined postpunk, glamrock, and new wave, evolved into among others darkwave, electronic body music (EBM), dark industrial, gothic rock, deathrock, gothic metal, medieval gothic, neofolk, paganfolk, apocalyptic folk, gothabilly, cybergoth, aggrotech, and hellektro. The list is incomplete: there are as many goth musical substyles as there are goth clothing styles. Like its visual self-fashioning, the scene's musical identity is marked by what Paul Hodkinson has called 'consistent distinctiveness' (Hodkinson: 28-33). The persistent gothness that characterises these varied musical styles tends to be described both in visual and in musical contexts as 'dark' (Gunn 1999: 39; Van Elferen 2012: 1-10). While black clothing and makeup are evidently an overarching characteristic of goth, their musical equivalent is harder to pin down: what is musical darkness?

Comparative analyses of a range of goth substyles show that these styles share a common compositional and productional basis: they each show a preference for minor keys and church modes, descending melodies, foregrounded bass structures, heavy echo and reverb effects, and slow to moderate tempos. These musical means are consistently used to convey gloomy lyrical themes such as isolation, nostalgia, un/death, and various types of hauntedness (Van Elferen 2012: 138-68). Although these harmonic, melodic, and rhythmical elements share historically developed connotations of sadness, and as such contribute to a recognisable musical gothness, they are not the key ingredient of the consistent distinctiveness of goth music. Gloomy lyrics, after all, also occur in every second pop or rock song, and so do minor keys; the church modes are also used in any guitar-dominated genre of popular music; ballads 
Pre-publication manuscript. Article accepted for Popular Music (2017 issue). Do not quote before publication.

in any genre are marked by slow tempos and descending melodies; the foregrounding of bass structures can also be heard in such varied styles as punk, metal, and EDM; and reverb effects are popular in reggae, dub, and metal also. The goth quality of 'musical darkness', therefore, cannot be defined by any one of these compositional choices, nor even by their consistent combination.

There is something else, a part of music that is not harmony or melody or rhythm but that is vital for musical aesthetics, something that is as shady as goth is. There is a difference between two utterances of the same minor harmony, the same descending melody, and the same slow rhythm at the same volume: that difference determines whether the one utterance is experienced as goth while the other one is symphonic, or metal, or indie. This difference is timbre, a musical quality that is just as ephemeral as the alleged darkness of goth itself: it is defined ex negativo as the difference between two tones with the same pitch and volume (Tagg 2013: 277). Certain timbres are able to add a consistent distinctiveness to Goth's gloomily connoted musical means of expression. It is timbre, the double negative of musical difference itself (that which is indescribable through what it is not), that renders goth music 'dark.'

All of the genre's substyles explore the variegated expressive capacities of timbre, experiment with new tone colours, and juxtapose contrasting shades of sound. Harpsichords and church bells, harps and bodhráns, radio static and analogue crackle add their own flavours to traditional rock sonorities. Hollow, booming, tormented, and distorted voices test the expressive limits of pop and rock vocal performance. Timbre-defining manners of articulation, such as flageolet, pizzicato, and glissando redefine instrumental performance in popular music. Musical textures as thick as industrial concrete or as ethereal as elven air provide three-dimensional timbral spaces in which melodies or rhythms roam. Timbrally orientated production techniques such as equalisation, amplification, sequencing, and panning are able to mould existing sounds into unexpected nuances of colour. The effects of these goth timbres can be further increased or intensified by one of the genre's favourite timbral manipulators: reverb.

Goth is in fact defined first and foremost by its timbre. The most often-heard description of goth music - that it is dark - is more accurate than it would seem. The haziness of the description notwithstanding, when subcultural participants, journalists, and academics refer to this music as dark they $d o$ refer to a very specific aspect of its sound. This particular aspect is timbre, the elusive musical quality of difference that is simultaneously crucial for aesthetic perception and does not allow for any more descriptive precision than that of subjectively coloured adjectives. Because of its aesthetic privileging of timbre, goth music offers a rare view on this under-theorised musical parameter. The genre puts timbre on an aural petri dish: an understanding of the darkness of goth timbre can lead to a better understanding of timbral difference and aesthetics in other kinds of music.

Goth, within its timbrally orientated aesthetic, favours a number of vocal and instrumental timbres. The following list is not an exhaustive taxonomy: these four vocal and two instrumental timbral types are an initial inventory of the main timbres employed in goth musical expression.

\section{The hollow voice}

The first and arguably most iconic of goth vocal timbres is what could be characterised as 'the hollow voice'. This timbre is produced by a lowered larynx, a relatively high singing volume, and a precise, sparse use of vibrato. It is usually aided by a strong reverb effect, which creates the acoustic semblance of a large space like a cathedral. Such wet sounds have been known to inspire exaltation and awe in listeners (Blesser and Salter: 2-3). This vocal timbre was first used by Bauhaus's Pete Murphy on the gothic ur-track 'Bela Lugosi's Dead' from 1979, and 
Pre-publication manuscript. Article accepted for Popular Music (2017 issue). Do not quote before publication.

has been described as 'a gothic rock archetype' and even as a 'Nosferatu vocal performance' (Carpenter 2012: 35). Other Batcave singers such as Siouxsie Sioux and Nick Cave of the Birthday Party had a similar hollow approach to vocal timbre and reverb. This timbre also characterises the darkwave vocals of Diary of Dreams's Adrian Hates and Deine Lakaien's Alexander Veljanov, as well as neo-Batcave singers like Beauty of Gemina's Michael Sele and Veil of Light's M, whose track 'Cold Skin' will be discussed below.

\section{The bombastic voice}

A second vocal timbre in goth is 'the bombastic voice', a voice type that is operatically inflected and has a booming sound. It is achieved by a lowered larynx, firm breath support, lush chest and head resonance, and full vibrato. Here, too, reverb adds the wetness of large acoustic spaces. The bombastic voice is especially popular in goth metal and medieval or pagan goth. Metal examples include After Forever/Nightwish's Floor Jansen and HIM's Ville Valo; medieval and pagan examples are Qntal's Syrah (Sigrid Hausen) and Wardruna's Gaahl.

\section{The tormented voice}

In contrast to these loud and large voices, 'the tormented voice' seems small and thin. This vocal timbre is achieved by doing the opposite of what classic singing pedagogy prescribes: the larynx remains raised, breath support is minimal, and vibrato is not controlled. The resulting sound is wobbly and agonised: reverb enlarges the agonised effect of a voice that is surrounded and haunted by emotions. The tormented voice has gained fame through The Cure's Robert Smith and can also be heard in the vocal performance of Alien Sex Fiend's Nick Fiend, Cinema Strange's Lucas 'Zampano' Lanthier. It is the main vocal expressive vehicle for Sopor Æternus and the Ensemble of Shadows's Anna-Varney Cantodea, whose track 'Dreamland' will be discussed below.

\section{The distorted voice}

Cyber and industrial goth subgenres in the late 1990s and 2000s used music software to turn the hollow, bombastic, and tormented vocal timbres of goth into technologically enhanced 'distorted voices'. Vocal performers like Combichrist's Andy LaPlegua, Suicide Commando's Johan van Roy, and Psyclon Nine's Nero Bellum screech their voice to oblivion over the equally distorted electronic soundscape of their tracks. Current rhythmic noise artists like Asche, Converter, and Synapscape hardly include vocal timbres in their tracks anymore. If human voices are used they occur in alienating samples, and are often so heavily distorted through multiple software manipulations that their human origins can barely be perceived.

\section{The instrument from other times}

Instrumental timbres in goth are as evocative as vocal timbres. An important category is 'the instrument from other times:' non-rock instruments used in goth music whose connotations create a juxtaposition between the contemporary and the historical. The instrument from other times occurs in all goth styles, but is unsurprisingly most often used in medieval goth. Estampie, Helium Vola, and Qntal make ample use of recorders, lutes, and fiddles to lend authenticity to their rewritings of early modern melodies and texts. Other goth bands prefer eighteenth-century instruments: Emily Autumn's main instrument is the harpsichord, and Sopor Aeternus explores all colours of Renaissance and baroque music from pipe organ to oboe. The decadence of the late Victorian Age is a major source of inspiration for goth subculture, and Paganini-esque violins are used by artists from Deine Lakaien to Soil \& Eclipse; Lacrimosa's use of the full range of symphonic timbres is informed by nineteenthcentury orchestration. 
Pre-publication manuscript. Article accepted for Popular Music (2017 issue). Do not quote before publication.

\section{The instrument from other places}

The 'instrument from other places' has a similarly dislocating timbral function in goth as the instrument from other times but is spatially rather than temporally orientated. This timbre, too, comes from a non-rock instrument used in goth music, but it stirs connotations of places rather than times: it conjures up worlds outside of day-to-day reality. This instrumental timbre is often used in pagan and folk goth styles, where bands like Omnia, Daemonia Nymphe, and Wardruna perform on a range of instruments from other places: hurdy-gurdies and bagpipes, didgeridoos and slideridoos, various types of harps and lyres, bodhráns and other percussion instruments add various kinds of ethnic and ritual colours to the musical design. The otherworldly power of such instrumental timbres inspired Omnia to dedicate an entire album to 'the magical musick of the Celtic Harp', which takes listeners on a 'beautifull [sic] and timeless musickal journey into the realms of Dreams and Faery' (Omnia).

\section{Temporal and spatial dislocation}

Many instrumental timbres combine these two types of dislocation. The organ with its connotations of churches and graveyards, the tubular or church bell, and the often-sampled call of the raven each connote the romantic yearning for a shadowy not-here-and-not-now that pervades goth culture. The celeste that turns Danny Elfman's film soundtracks into spooky fairylands operates through the same principles. All of these are timbral clichés of gothness, but clichés that remain effective because their timbral performativity so strongly suggests other times and other places.

The 'machinic' goth timbre's associative performativity leans on both temporal and spatial displacement. Rather than the past, this timbre refers to the future, and rather than pagan worlds, this timbre evokes industrial or science fictional spaces. In cyber and industrial goth, such machinic timbres are put in stark contrast to human timbres, even if the latter are often heavily distorted. Depeche Mode was an early example of this timbral juxtaposition. The band's sound was defined by the electronic slickness of the synthesizer, which blended perfectly with David Gahan's hollow vocal timbre. Since the 1990s, goth industrial acts like Nine Inch Nails refrain from acoustic timbres, favouring electronic, digital, and digitally distorted timbres. In these experimental genres the timbral difference between the human and the non-human is all but eradicated.

\section{Articulation and production}

Goth musicians further perfect their preferred instrumental and electronic timbres by using articulation and production techniques. From violin flageolet and pizzicato cellos to amplitudinal refinement and wide reverb, goth's engagement with timbre is simultaneously more varied and more precise than that in any other genre of popular music. Despite the multitude and range of timbral types, each of these is typically goth. This musical belonging is aided by these timbres' embedding in the harmonic, melodic, rhythmical and productional basics of the style. The 'gothness' of these timbres is so immediately recognisable that only a few bars of their sound - despite being 'in the dark' about how to describe this aspect of music - identifies them as belonging to that murky zone of sound and subculture that is goth.

More than any other musical quality it is timbre that makes music goth. Marilyn Manson and Nine Inch Nails's cover of Madonna's 'Like a virgin,' for instance, is worlds apart from the original pop song. Manson's usual vocal self-mutilation is further warped by Reznor's mastery of production technology, which intensifies the timbral expression in the vocal track by adding reverb, lower octave doubling, and panning. Manson's and Reznor's timbral manipulations cause a musical metamorphosis: the difference between the two songs is not 
Pre-publication manuscript. Article accepted for Popular Music (2017 issue). Do not quote before publication.

lyrical, harmonic, not melodic, and not rhythmical, but only timbral. Timbre alone can turn a pop song into a goth song: difference and identity, after all, are closely linked.

\section{Timbral metonymy}

Robert Walser argues that a large part of the genre definition of metal is determined by the timbres of vocal grunt and guitar distortion, with the latter adding lower harmonics to the power chord (Walser 1993: 41-4). He remarks that timbre has an important genre signifying function in popular music in general: 'Before any lyrics can be comprehended, before harmonic or rhythmic patterns are established, timbre instantly signals genre and affect' (Walser 1993: 41; cf. Zak 2001: 64-5). Besides musical genre, timbral difference also identifies individual styles. To mention but a few examples, Jimi Hendrix's use of guitar amplification and feedback, Eric Clapton's use of sustain on the Fender Stratocaster, Louis Armstrong's embouchure and breathing technique, and the Neptunes's studio production of dry acoustics and compression are each highly recognisable timbres, and each identifies a certain individual or group of individuals.

Through a process of significatory connection these timbral idiosyncrasies become metonyms for musical identities. Timbre is an important marker for musical difference, and as such seems to construe musical identity: that particular type of Strat sustain is Clapton, that type of extreme power chord distortion is metal. Similarly, a timbrally encapsulated goth musical identity seemed to have been born with the timbres that roamed 'Bela Lugosi's Dead.' The combination of Peter Murphy's hollow voice, Derek Thompkins's productional focus on ominous reverb and bass structures based on his experience of dub production (Carpenter 2012: 40), and the eerie environmental sounds borrowed from horror cinema was immediately etched in the public ear as the superlative musical equivalent of goth darkness. If genre is, as Joshua Gunn has argued, 'fundamentally an assemblage of preferred adjectival codes' (1999: 36), then it is no wonder that timbre, the quality of music that is shrouded in adjectives describing difference, is so crucial for genre. Bauhaus's timbral orientation cannot be described more precisely than through an assemblage of adjectives: it is hollow, ominous, and eerie. It is exactly that doubly shadowy orientation that made Bauhaus stand out from the neighbouring styles of post-punk, glamrock, and dub. This standing out started a process towards genre identity that is based on the perception of timbre. The recognition of timbral difference (Bauhaus sounds different than other popular music: hollow, ominous, and eerie) leads to adjectival assemblage (we shall call this hollow, ominous and eerie musical genre goth) and then to metonymy (the word 'goth' indicates any timbres that may sound similarly hollow or ominous or eerie), and gradually metonymy becomes synonymous with identity (goth is a recognisable genre that is hollow, ominous, eerie, and any other adjective that may be added to the assemblage).

Unpacking this process highlights precisely why the equation of timbre and identity is problematic as well as compelling. It is based on metonymy, which is an arbitrary signifier: this linguistic signifier, moreover, is used to identify qualities of sound that defy description.

\section{Track \#1: Veil of Light, 'Cold Skin'}

The track 'Cold Skin' by Swiss neo-goth act Veil of Light, a one-man project of the elusive artist 'M,' exemplifies the processes of timbral metonymy. The project's self-description and its music illustrate both the ways in which goth genre identity appears to be dependent on 
Pre-publication manuscript. Article accepted for Popular Music (2017 issue). Do not quote before publication.

timbre, and the ways in which this dependence is contentious. On the band website the project is placed explicitly in the goth tradition of timbrally evoked gloominess:

At first Veil of Light might come across as cold. It's an easy mistake to make, their grand gothgaze is certainly steeped in... melancholy and desolation. But as you become enveloped in the crystalline synth swaths, the mechanical rhythms, and the screeching guitar feedback, you feel a [sic] oddly at ease. Comforted. Like pulling your coat tighter as you walk down a [sic] empty, rain-wet autumn street. (Veil of Light)

In this description we see the process from timbral difference through adjectival assemblage and metonymy to genre identity at work. Without even playing their music, Veil of Light introduces what Lelio Camilleri calls a 'sonicprint,' a sounding fingerprint created by studio production (2010: 210). The crucial components of the band's sonicprint relate to timbre, and are described by way of adjectival and adverbial constructions: cold, grand, steeped in melancholy and desolation, crystalline, mechanical, screeching, oddly at ease, comforted, empty, rain-wet, autumn. Together this adjectival assemblage forms a metonymy for what the band describes as their sonic identity: a gothgaze, which appears to be a combination of goth and shoegaze, as well as a goth outlook on the world.

The concrete sound of the musical elements that afford this gothgaze demonstrates how the very fact of timbre's ephemerality invites such sustained inscriptions. 'Cold Skin' was a modest hit in 2013 and is typical of Veil of Light's style. The most immediately noticeable elements of this track are timbral: the heavy reverbs and dubs on all tracks, the spatial foregrounding of bass and rhythm sections, the obfuscation of the lyrics by this acoustic design, the dynamic processing that blurs all foregrounded bass parts themselves. As Michael Bibby has demonstrated, this hi-fi production style was characteristic of Factory Records's Joy Division recordings, and it is clear that Veil of Light's production references this early goth style (Bibby: 239-53). Interestingly, despite this productional focus on lower range sound, the low-cut equalisation of guitar, drums and vocals put emphasis on the higher resonances. EQ is a powerful timbre manipulator, and here it has a remarkable effect. The ensuing amplitudinal contrast between foregrounded bass-only structures on the one hand and backgrounded or muffled treble-only structures on the other creates the sonic illusion of a vast acoustic space (cf. Camilleri 2010: 202-5). The many reverbs in the track resonate through this musical space, but are not its primary generators. This creation of amplitudinal spatiality by way of strong equalisation contrasts is another link between Veil of Light's timbral design and oldschool goth: similar effects occur in Bauhaus's records (Carpenter 2012: 40). M's 'hollow' timbre, moreover, is so reminiscent of that of Ian Curtis that it almost seems imitative or parodic: the reverb, which makes his voice appear even more hollow, strengthens this similarity. The fact that the melody of the chorus is sung in at almost unbearably flat pitch seems to affirm the downward spiral of goth gloom. The track's non-timbral musical attributes strengthen the connection with Joy Division, Factory Records, and Batcave: the song is written in the minor key of F sharp, the bass lines move in fast patterns, and the song ends with the lingering dominant chord C-sharp without moving back to the tonic.

Even though Veil of Light's sonicprint is delineated by allusions to earlier goth styles, its timbral gestures do not afford anything more concrete than such vague allusions. Record production research acknowledges simultaneously the importance of timbral associations and the unquantifiability of these associations. Veil of Light's elaborate description of the intended meaning of their privileged timbres is a version of what Simon Zagorski-Thomas calls 'timbral staging,' the idea that timbres are carefully shaped in production in order to create certain intended meanings (81-3). Allan Moore speaks explicitly of the signification of timbre, but emphasises that timbre rather creates emotional gestures than concrete meanings (2012: 45-9). Albin Zak is even more careful, arguing that the 'rhetorical aspect of timbre' is 
Pre-publication manuscript. Article accepted for Popular Music (2017 issue). Do not quote before publication.

driven solely by connotations and leads to timbral symbols that suggest 'dialogues and resonances beyond the boundaries of the track' (2001: 62). Zak's cautious approach seems the most appropriate here, as it is through such dialogues with and resonances of other artists that Veil of Light achieves its sonic identity.

While the production of timbre, in other words, is characterised by great precision, that precision is absent - absolutely, maddeningly, ecstatically absent - in its significatory performativity. Timbral production and timbral signification are each other's inversion: timbral production is a very precise photo negative whose concrete features, when exposed to air, shine briefly and then evaporate. Timbre, even when it is as precisely produced and staged as in 'Cold Skin,' does not in and of itself mean anything. It cannot even be clearly described except in adjectives and historical comparison. Precisely that significatory elusiveness allows for endless inscriptions of meanings such as those on Veil of Light's website: the collection of timbres that they consistently use and which identifies their sonicprint becomes a metonymy for the band's 'grand gothgaze' identity - an identity which is based on the allusion to concrete signification which is always absent upon closer inspection. Thus, the negation at the heart of timbre's definition as musical difference extends to its signifying capacities, and, through the evasive route of metonymy, also marks the musical identities it shapes. Timbre is a tangibly present quality of music, but it defies definition; it appears to signify a great deal and yet it does not; it seems to form musical identities and yet these identities are built on absence.

\section{The grain and its limits: timbral paradoxes}

The paradoxical condition timbrale of present absence (of definition, signification, and identification) has been the cause of much scholarly debate. Attempts to find clear timbral signification and identification can only succeed in the analysis of vocal music, as the singing voice involves the observable signifying process of language and the observable identification process of embodiment: the presence of lyrics allows focus on the relation between timbre and words, and the presence of a singer allows focus on the relation between timbre and bodies. As timbre, however, does not only occur in vocal music, these approaches are incomplete at best.

Roland Barthes famously theorises the meeting between voice and language as 'the grain of the voice' (1977). Although Barthes recognises that music is not comparable to language, he argues that music does signify, and that its signified is the body: 'music is a field of signifying [signifiance] and not a system of signs, the referent ... is the body. The body passes into music without any relay but the signifier' (Barthes 1985: 308). This musical type of signification, he argues, is sublimated in the grain of the voice. The grain incorporates timbre but extends to the expression of linguistic content (Barthes 1977: 185). A compelling singer, Barthes argues - here he discusses the specific baritones of Charles Panzéra (which he admires) and Dietrich Fischer-Dieskau (which he dislikes) - makes something of his own body audible in his performance. It is the friction between this musical corporeality and language that adds specific signification to the vocal performance. The grain is 'the body in the voice as it sings, the hand as it writes, the limb as it performs' (Barthes 1977: 188).

Because many subsequent musicological and philosophical evaluations of voice and timbre have been founded on this pioneering essay it is important to try and determine exactly where his arguments do and do not hold up. Besides the peculiar subjectivity regarding baritone performances, his arguments fail to be altogether convincing in three ways. The essay - and the literature in its wake - operates on the basis of a series of conflations:

(1) Timbre is conflated with voice; 
Pre-publication manuscript. Article accepted for Popular Music (2017 issue). Do not quote before publication.

(2) Vocal music has text, and text in music is conflated with musical signification;

(3) Vocal music is produced by a body, and the musical body is conflated with musical identity.

These propositions lead to a syllogistic sort of reasoning in which timbre is thought to be about signification and about identity, and in which these two aspects of vocal timbre are thought to be inseparably related. As a result Barthes is able to state that the materiality of the voice equals 'the emergence of text in the work' (Barthes 1977: 188), thus not only reducing the voice to talking subjectivity, but also equating the timbral dimensions of musical identity and signification. Each of the three presumptions at the heart of Barthes's argument, however, has its own problems:

(1) Timbre is not limited to the human voice;

(2) Musical signification, if it exists at all, is not reducible to language;

(3) Musical identity, if it exists at all, is not reducible to physicality.

The equation in argument 1 undermines the validity of the syllogistic equation of timbre with signification and embodiment. The fact that the other two arguments are tenuous in and of themselves, though, further complicates matters.

Argument 2 about musical signification has been the subject of musicological debate at least since poststructuralism, and Barthes himself was involved in such debates. The relation between music and signification is a difficult one at best: this is why Barthes argues that music is not a system of signs but a field of signifiance. But is it even that? Lawrence Kramer argues that music 'does not act as a sign, despite being highly meaningful' (Kramer 2002: 157). He contends that music is rather a 'sign fragment, the signifier of a veiled or unrealised signified' (ibid: 156). This would suggest that any process of signifiance in music is always interrupted, or shrouded, or distorted. Music qua music does not signify anything, it never even refers. Its performativity, however, does have strong emotional and mnemonic effects, which is why music can be perceived as 'highly meaningful': these effects are often subjectively understood by listeners (or groups of listeners) as signifieds. While no part of music is in and of itself a sign, it may therefore sometimes take on the appearance of a sign. When Barthes considers music a field of signifiance he thus zooms in on only that arbitrary part of musical performativity which may lead to the semblance of signification, but overlooks those parts of musical performativity that have nothing at all to do with signification. He thereby ignores what is indisputably the most important characteristic of music qua music: the mindless and meaningless flow of playing, improvising, or listening that Carolyn Abbate calls the 'drastic' aspect of music (Abbate 2004).

Of all musical parameters, timbre is the quality with the least univocal relation to signification. Paradoxically it is also the musical quality to which listeners most often ascribe a significatory function. Certain guitar distortions are taken to signify 'metalness'; choir singers use 'light' vocal timbres to signify the 'lightness' of certain passages in their repertoire; and even the 'smooth' or 'thin' timbre of a production is understood to signify smoothness or thinness (Moore 2012: 45). Such interpretations of timbre are based on metonymic construction. As the Veil of Light analysis illustrates, timbre's relation to signification is a shadow play that masks the absence of any form of signification, even that of metonymy. Despite the misleading fact that they sing text, therefore, the vocal timbres on which Barthes and subsequent theorists base their arguments cannot be reduced to signifiers. Although Barthes is keen to perceive text in the musical work, voice - precisely in its timbre - does not only represent language. If it did, vocal timbre would simply not matter, and there would be no difference between Madonna's and Manson/Reznor's renderings of 'Like a Virgin.' It is even harder to make the claim of signification or even signifiance work for instrumental, electronic or digital timbres that do not have a direct connection with text. 
Pre-publication manuscript. Article accepted for Popular Music (2017 issue). Do not quote before publication.

Even if we accept that timbre can only ever be an obfuscating signifier, a non-sign referring to a 'veiled signified' (Kramer) which itself is hidden in metonymy, it can be argued that timbre's tangible presentness appears to signify at the very least its own physicality. Component 3 of Barthes's assessment of voice seems to be straightforward enough: timbre signifies 'the body in the voice as it sings, the hand as it writes, the limb as it performs' (Barthes 1977: 188).

The materiality of a timbre helps us recognise important aspects of its origin: we can hear cigarettes on Nick Cave's and Ville Valo's voices, for instance, and the difference between Madonna's and Manson/Reznor's 'Like a Virgin' is that of timbre-producing bodies and machines. This down-to-earth part of Barthes's argument has inspired important methodological innovations. Allowing a movement away from score analysis, carnal phenomenology affords a turn towards to the musicking body that was overlooked in traditional musicology. It has led to insights regarding the political performativity of gendered, ethnic, and queer voices (e.g. Abbate 1993, Bonenfant 2010; Eidsheim 2015; Goehr 1998; Middleton 2006). ${ }^{1}$ Extending this phenomenological angle to non-human voices, Don Ihde argues that 'every material thing has a voice' (2007: 190). Analysing the sound of striking a wooden lectern with a knuckle alongside the sound of an oboe within that of an orchestra, he contends that the voices of things bespeak their materiality, their shapes and internal dimensions. He contends that all of these should be considered identities, but explicitly non-textual identities: 'The voices of things are not the voices of language. For what the voices of things bespeak is a kind of direct sound of their natures: materiality, density, interiority, relations within experienced space, outward hollows and shapes; complex, multidimensioned, often unheard in potential richness, but spoken in the voices of things' (Ihde 2007: 192). From these observations Ihde concludes that timbre, which he terms 'expressivity', represents 'the who of voice' (195). The physical origins of timbre, in this theory, convey a clear material identity: strings are the identity of stringed instruments, wood is the identity of woodwinds, and brass is the identity of brass.

Both in Ihde's 'expressivity' and Barthes's 'grain of the voice', thus, the physicality of sound is taken as a form of musical sound and individual expression: even if a timbre cannot be a signifier of anything textual or linguistic, their reasoning goes, it does signify the material body that produces it. But timbral performativity is not only material, and timbral materiality cannot be equated with signification. Manson \& Reznor's 'Like a Virgin' does not simply mean 'Manson \& Reznor,' just like Madonna's version of that song does not just mean 'Madonna.' Barthes's contention that the singing voice points to the identity of the singer is surprising in the light of his own earlier writing. Abbate critiques this remarkable u-turn back to signification, stating that ' $\mathrm{r}$ ] ather than killing the author, Barthes proposes the rebirth of an author "inside" the artwork, one that reveals herself in the "grain" of the voice(s) that speak what we read (hear)' (Abbate 1993: 232). The same could be said about Ihde's 'the who of voice': the material aspects of timbre are undeniable, but that materiality is not necessarily the same as identity, not even in an exclusively carnal phenomenology. Moreover, many of the ways in which timbral embodiment has been interpreted ('hollow' vocal timbres and 'magical' instrumental timbres in goth, 'aggressive' timbres in metal, and so on) point away from materiality rather than to it.

The issues related to timbre discussed so far should be considered not exclusively but accumulatively. Timbre is simultaneously is and is not a sign, and when it is a sign it simultaneously does and does not point to the material body that generates it. A move away from this accumulative ambivalence by allocating an identity to timbre is an reduction of timbre's paradoxical phenomenology. Timbre's performativity exceeds the confines of voice and body and has an unstable relation to signification and identity. Barthes's phonological grain, thus, offers a start for a theory of timbre, but an incomplete one. Timbral metonymies 
Pre-publication manuscript. Article accepted for Popular Music (2017 issue). Do not quote before publication.

like the ones listed in the first paragraph of this article explicate the problem. If they act as signifiers, then only for signifieds of an unknown 'beyond' - a fantastic pastness, a fictional paganness, an imaginary spookiness - and if they represent material identities beyond soundwaves then these identities themselves are shrouded in Gothic veils. Goth timbre problematises the very ideas that Barthes put forward. The reverbs that envelop its timbres invite even more questions about precisely these aspects of timbre: where do these echoes point, what body produces them, and when did it do that? All we know is that they are there but not there, not of this place and not of this time.

\section{Track \# 2: Sopor Aeternus and the Ensemble of Shadows, 'Dreamland'}

In order to understand how timbre defies language, signification and embodiment, I'd like to introduce the next example by way of a close listening alone. Not obfuscated by prior knowledge regarding the provenance of the song, its lyrics, the singer, or genre, our ears are open to timbre's intense performativity. The next paragraph will then relate this close study of timbre in the track to its musical, poetic, and subcultural context.

A door creaks. Its reverberating sound rises up in a slow, minimal, suspenseful glissando that pans from the left front to the middle rear. This door has not been opened for a long time, or it would not creak so much. The space to which this door leads must be very large, made of stone, and empty, or the reverberation would not be so tangible.

Just as the door seems to swing fully open, a bass guitar and a standing piano play $\mathrm{F}$ and A flat respectively. The minor third strengthens the eeriness of the creaking, the deep sound of the bass, and the shrill overtones of a tinny-sounding, sick (or maybe plucked?) piano: their collective timbres reverb through the empty space. The space is large, empty, but not silent. Far in the background white noise pans through all corners like midnight wind. On the second beat of an andante 4/4 measure a tubular bell chimes, and the creaking is repeated in irregular rhythms at slightly lower volumes, panning from right to left to middle in wide reverb. Is this empty space a crypt of some sort? Was that creaking caused by a door in the first place? The acoustic displacement makes it sound rather like the screeching of an unworldly animal. Where is this space?

In slow units of two bars each, the bass guitar plays its sustained Fs while the piano plays low minor third semiquavers, repeating a melancholy downward leap from $\mathrm{A}$ flat to $\mathrm{F}$ in a repeated motif. At the end of each first bar a B-C grace note motif is played on harpsichord. Far in the background a second piano motif is audible: it simply states the minor F-C-A flat-F in punctuated quavers. In the right foreground of the soundscape a third piano part ends each second bar with a semiquaver motif of repeated Cs leading to B on the first beat of the third bar. This motif introduces a repetition of the first two bars based on $\mathrm{E}$ minor instead of $\mathrm{F}$ minor. The repetitive sequence is an echo of an echo, driven by absence and allusion - a semitone lower, without the piano left hand and the harpsichord right hand, with the church bell now appearing on the second half of the second beat in even stronger syncopation, and an inversion of the semiquaver piano motif now leading from repeated Bs back to the $\mathrm{C}$ in the $\mathrm{F}$ chord: then it all starts again, floating between $\mathrm{F}$ minor and $\mathrm{E}$ minor without direction, goal, or solution.

The two-by-two bar structure continues for more than a minute, long enough to make the listener palpably aware of just how strange this sonic world is: she is invited into an empty timespace in which antique instruments reverb bitonally, through which cold winds sweep, and where unearthly doors creak. Then a tormented voice begins to mutter barely comprehensible words into the soundscape in which the windy noise, that now appears to be 
Pre-publication manuscript. Article accepted for Popular Music (2017 issue). Do not quote before publication.

louder than before, blows endlessly from $\mathrm{F}$ to $\mathrm{E}$ and back. Placed in the middle range over the descending thirds of the piano, this voice could be heard as a low alto but also as a tenor.

Sung with a raised larynx but not in falsetto, recorded at low volume but croaked rather than whispered, it seems not to sing but to sob or cry, its effect that of a guttural rasp rather than a singing voice. The voice's melody is bleak, consisting only of repeated A flats descending to $\mathrm{F}$, and repeated Gs falling to $\mathrm{E}$. Within this limited melodic range, however, there is no end to the shades of vocal colour in the singer's performance: in abrupt articulation but with a legato arching over long stanzas, alternating between lower and higher overtones, chest and head resonance and yet always in perfect pitch, these sobs are at least as enigmatic, ephemeral, intangible as the sonic backdrop into which they fall. The singer's intense performance is thin and pianissimo, and should therefore by all means be drowned in the louder natural volumes of bass, church bell, and synths: microphone placed close by, mixed down into an intimate 'proxemic zone' (cf. Moore 187).

\section{Timbral excess}

The track discussed in the previous paragraph is called 'Dreamland' and appears on Sopor Aeternus and the Ensemble of Shadows's 2013 album Poetica, which was recorded by Patrick Damiani at Tidalwave Studios in Karlsdorf, Germany. The lyrics for the album are taken from Edgar Allen Poe's work, and this particular track is a musical setting of 'Dream-Land' from 1844.

By a route obscure and lonely,

Haunted by ill angels only,

$[\ldots]$

I have reached these lands but newly

[...]

From a wild weird clime, that lies, sublime,

Out of Space and out of Time.

Do these lyrics or the fact that they were written by Poe matter for the initial appreciation of this track?

Sopor Aeternus is the solo project of Anna-Varney Cantodea, who describes her own music as 'Gothick' and presents herself as the 'Goddess' of the goth scene (Sopor Aeternus). The band name means 'eternal sleep,' and Cantodea's pseudonym combines James Malcolm Rymer's vampire penny dreadful Varney the Vampire (1845-7) with a Latin composite that can be translated as 'I sing the goddess.' She is reluctant to give interviews and 'refuses to perform her magic(k)al work live in front of a human audience' (Sopor Aeternus). Musically, Sopor Aeternus blends together medieval, baroque, folk, dark wave, and cabaret styles and instrumentations. Cantodea refers to her own music as 'music(k) for dead children' that expresses 'pain, isolation, depression, token suicides and the desperate search for the 'sacred reunion' (Sopor Aeternus). Sopor Aeternus's performance, in short, is superlatively goth, and the artist has a dedicated cult following in the scene. Does the explicit gothness of the author's and her audience's subjectivity influence an initial listening experience?

Born male and never operated, Cantodea rejects fixed gender and describes herself as an 'inter-sexual goddess' (Sopor Aeternus). While some album covers portray her naked without genitals or breasts, she is mostly photographed in Renaissance style, in long black dresses with a shaved head featuring only a tuft of long, often ornamented hair in the middle. Her many piercings, long finger nails, and tormented facial expressions are complete her complex physical self-representation. Does her unusual corporeality have any bearing on musical experience? 
Pre-publication manuscript. Article accepted for Popular Music (2017 issue). Do not quote before publication.

The answer to these questions is no, none of these aspects of signification and identity matter for a first appreciation of this track - but its blend of timbres does. The creaking door, the harpsichord, the sick-sounding piano, the church bells, Cantodea's tear-ridden voice: all these timbral elements together evoke an accumulation of alienation and suspense. The timbral production of the track adds to this ambiguity: there is acoustic saturation in some areas of the soundbox but not in others; the reverb time changes from layer to layer; microphone distances vary from one sound source to another; some sources pan and move through the musical space. As a result of this carefully ambivalent production, a thin but fuzzy texture is created in which spaces within spaces seem to emerge. This timbral precision enlarges the musical ambiguity of the track's bitonality ${ }^{2}$ and its mournfully repeated melodic patterns to almost uneasy proportions. Nothing is certain about this song: there are no clearly identifiable sound sources, is no straightforward timbral staging, no meaning and no identity the opposite of any of these, if anything at all. What are these sounds? Where do they come from? When were they uttered, and by which impossible beings? 'Dreamland' demonstrates the photo negative quality of timbre: its production requires a tremendous amount of precision, but when it is exposed to the world its roots, its meanings, and its identity evaporate as if they never existed.

Perhaps they didn't. Did that strange voice sing 'out of space and out of time,' right before that dislodging SF-Western oscillator glissando?

\section{Timbral desire: surplus and lack}

Timbre's paradoxical phenomenology is operative through excess, a spilling over of the boundaries of signification and identity. It signifies and it is embodied, but it is importantly more than both of these things. There is a transgression of limits inherent in timbre, a surplus of signification that is also a void. Goth would not be goth if it did not exploit this characteristic of tone colour. 'Dreamland' is an illustration of how problematic the notions of timbral identity and signification are - timbre simultaneously affirms and defies even the most ephemeral of them. As wonderful as Poe's poem is, as interesting as Cantodea's intersexual body may be: these factors have no influence at all on the initial musical appreciation of the remarkable timbres in this song, which incite a direct immersion into an undefined, but purely musical, timespace. Lyrics, biographical information, and embodiment may add to the effect timbre has, but they do not even begin to cover timbre's immersive force. The track's meticulously produced timbres seem to function as signs pointing towards musical signifieds, genre, or identity, but upon closer inspection there seem to be too many signifieds there. Do we hear creaking doors or percussion instruments? Large spaces or smaller ones? Empty or full spaces? Churches or vaults? Instruments from the past or from the future? Is the singer male or female? Are these tormented or creepy voices? Is this a sad song or a happy one? Is this goth or science fiction music? All, some, or none of the above? The surplus of signification leads to a collapse of meaning. These timbres are not signs. They are merely sounds. Not even that - they are the difference between sounds, and the negation that defines them extends to their signifying performativity.

For all its physical presence, timbre is a negative, a void. But precisely because it is simultaneously so undeniably present and so resistant to signification and identity, this void is crucial for musical aesthetics. Timbre is the first thing that strikes - tangibly, physically strikes - listeners in musical experience, and its sway sets in motion the drastic, mindless flow of musical immersion. Because of its powerful performativity listeners project meanings onto its non-signifying void. These projections are individual and changeable, and they consist of vague adjectival or metonymic assemblages, but they are consistently filled with the 
Pre-publication manuscript. Article accepted for Popular Music (2017 issue). Do not quote before publication.

profoundest of fantasies, anxieties, and desires. Timbre appears to signify because we desire to fill its presence-that-is-absence with meaning: its excess spills out of the gap it conceals.

This aspect of timbre has been theorised by Mladen Dolar, whose book A Voice and Nothing More (2006) begins where Roland Barthes ended: with the voice's relation to signification and embodiment. In terms of signification, Dolar emphatically steps away from phonology, which he claims 'stabs the voice with the signifying dagger' (19). With regards to embodiment, Dolar recognises the voice's detachment from the body that produces it, arguing that voice is a 'plus-de-corps: both the surplus of the body, a bodily excess, and the no-morebody, the end of the corporeal' (71). Instead, he argues that voice represents the surplus of language and body that Jacques Lacan calls the objet petit $a$, the unattainable object-cause of desire:

So the voice stands at a paradoxical and ambiguous topological spot, at the intersection of language and the body, but this intersection belongs to neither. What language and the body have in common is the voice, but the voice is part neither of language nor of the body. The voice stems from the body, but is not its part, and it upholds language without belonging to it, yet, in this paradoxical topology, this is the only point they share - and this is the topology of objet petit $a$. This is where we could put Lacan's pet scheme of the intersection of two circles to use in a new application: the circle of language and the circle of the body, their intersection being extimate to both. [...] For what Lacan called objet petit a - to put it simply — does not coincide with any existing thing, although it is always evoked only by bits of materiality, attached to them as an invisible, inaudible appendage, yet not amalgamated with them: it is both evoked and covered, enveloped by them, for 'in itself' it is just a void. (Dolar 2006: 73-4. Italics in original)

Dolar's assessment of the human voice answers some of the questions regarding the voice's paradoxical relation to language and embodiment that were left open by Barthes. In psychoanalytical terms this relation is marked by a surplus that can be traced back to the absolute extimacy of the objet petit $a$. The idea that vocal timbre works as the object-cause of desire would explain listeners' eager inscriptions of (fantasies of) meanings onto this tangibly present but ephemeral quality of sound. Goth's remarkable timbres, for instance, effect a powerful sonic manifestation of the longing for different realities expressed in goth lyrics and culture (Van Elferen and Weinstock 2015: 42-3). The goth examples discussed here illustrate how this desire is inscribed in timbre, and how this inscription into the most ungraspable of musical qualities underlines the unattainability of the desired state. The timbres in the first paragraph seem to point to a hazy form of musical difference which has become adjectivally connoted as the hazy identity formation of 'goth'; Veil of Light's track 'Cold Skin' shows how these types of signification and identity are based on the absence encapsulated in metonymy; and Sopor Aeternus's 'Dreamland' mercilessly reveals that even timbral metonymy is built on nothing but an imagination driven by the desire for an unknown other time and space.

Like Barthes, however, Dolar does not primarily study timbre, but the human voice. This focus betrays the psychoanalytical preoccupation with subjectivity: in the search for 'the nature of the subject implied in [voice]' the vocal objet petit a (object voice) becomes equivalent with the interior subject (Dolar 2006: 23). When Dolar does discuss timbre, therefore, it is unsurprising that he describes it the 'individuality' of the voice (22). The human subjectivity that Dolar finds in the object voice is thus as much a form of signification and identity as Barthes 'grain of the voice' and Ihde's 'the who of voice'. He argues that a large part of the voice's significance lies in its political and ethical impact (83-124). Here psychoanalysis follows a similar trajectory as carnal phenomenologies of voice do, and curiously curves back to the areas from which it claims to step away. Reducing timbral theory 
Pre-publication manuscript. Article accepted for Popular Music (2017 issue). Do not quote before publication.

to the human voice does not cover the full field of vocal, instrumental, and productional timbre. Moreover, a focus on the voice easily leads to towards signification, embodiment, and subjectivity. While these are undeniably important aspects of timbre, they are not the only aspects of timbre, which exceeds any and all of these quantifiers.

Once again timbre presents a paradox: it is and is not the object-cause of desire. Even though tone colour is immaterial, absent, and desired enough to be a figuration of the unattainable objet petit $a$, it is simultaneously too audibly material, too directly present, and therefore too accessible to be an 'inaudible appendage of materiality' (Dolar 2006: 74). Timbre' accumulative paradoxes prove difficult to overcome. Perhaps the important point to make here is that they cannot and should not be overcome. Perhaps a theory of timbre is only possible if does not just account for, but is based on the same paradoxes that make this musical quality so hard to grasp. Because these paradoxes are instrumental for timbre's role in musical appreciation, I would argue that such a theory would have to be developed as an aesthetics of timbre.

\section{The aesthetics of present absence}

The stepwise assessment of timbre's most often theorised characteristics affords the recognition that its key characteristics are marked by evasiveness or paradox:

(1) In/stability. Timbre may be created by vocal, instrumental, and/or productional sources, but it is unstable, as a multitude of factors including pitch, texture, EQ, reverb, and spatialisation influence its sonic appearance.

(2) Non/signification. Timbre is not linguistic, but it sometimes acquires the function of a sign. Even when it does, however, it still points to something inconcrete and unknown.

(3) Non/identity. Timbre has clear material and/or corporeal roots, but it does not necessarily possess an identity, but sometimes it does identify someone or something. Even when it does, however, it identifies someone or something inconcrete and unknown.

Steven Shaviro notices that Dolar's psychoanalytical focus overlooks the 'aesthetics of the voice,' which he deems key to an understanding of the topic (Shaviro). Judging from the list of individual singers he names as examples of such an aesthetic, he refers to vocal timbre here: rather than an assessment of the meanings of voice, he wants an assessment of the more immediate, purely sonic aspects (i.e. timbral) of voice and their appreciation. Shaviro pinpoints precisely what is lacking not just in Dolar's book, but in most existing theories of timbre, which tend to be based on one or more of timbral characteristics listed above. A theory based on the aesthetics of timbre is able to complement these approaches: where necessary, it can defy or even negate the relevance of emphasizing timbral meaning and embodiment. Such a theory, thus, can include all the paradoxes at the root of timbral phenomenology. Rather than forcing an unrealistic choice between, say, 'electric guitars signify masculinity' and 'electric guitars do not signify anything apart from the joy of playing with sound', an aesthetic theory of timbre emphasises that tone colour is so powerful precisely because it does both at the same time and neither.

The aesthetics of timbre revolve around gaps: those between difference and identity, meaninglessness and signification, lack and surplus, production and performance. The aesthetic moment is brief and powerful: it occurs in turning the photo negative to light, within the event of its evaporation, it occurs because of its evaporation. Tone colour establishes an aesthetic of the moment, of the event. This evental aesthetic is marked by what can only be described as 'present absence:' while timbre is audibly and tangibly present, the experience of this presence indicates the absence of anything concrete, anybody in particular. Shaviro argues that the aesthetic experience of voice leads listeners into a 'labyrinth' (Shaviro). The 
Pre-publication manuscript. Article accepted for Popular Music (2017 issue). Do not quote before publication.

inconcrete and unknown lines of flight established by timbre are precisely the core of its aesthetic attraction, and this is why its 'meanings' will always be as vague as they are enchanting: the fantasised pastness of harpsichords in popular music, a grand gothgaze produced by a nostalgic studio, or 'slowhand' guitar sustain. Timbre's aesthetic significance is only that of an intensified here and now, a time and place engendered by the drastic event of musical difference. And even the event of timbre itself is paradoxical, as its temporal ephemerality contradicts the seeming infinity of its immersion. It is the finitude of the event of tone colour, the ephemerality of its occurrence, the series of gaps it establishes, that defines it as an aesthetic quality. Amending the extimacy of the objet petit- $a$ that Dolar describes, which is tied to subjectivity by way of desire, timbral aesthetics must be thought of as a more layered type of outside: the outside of present absence which coexists with the inscriptive process operated by desire.

Timbre takes listeners into an unknown outside. It is important to note that this is not just true for goth music: the reach of timbral aesthetics is vast, pervading popular and classical music alike. Goth, however, is a specially poignant case of timbral aesthetics. With its penchant for shadows and veils, beyonds and outsides, this genre has developed a sophisticated timbral aesthetic as its main musical vehicle. Goth's musical darkness consists of hollow and tormented voices, instruments from other times and other places, and production techniques that create impossibly reverberant virtual spaces. Quoting Edgar Allen Poe in Anna-Varney Cantodea's timbre and enveloped in Patrick Damiani's production technology, Goth's dark timbre truly does 'lie, sublime, out of space and out of time'. Because it has has made the aesthetic of present absence its main musical parameter, Goth music opens the door to an exploration of the timbral labyrinth. 
Pre-publication manuscript. Article accepted for Popular Music (2017 issue). Do not quote before publication.

\section{Bibliography}

Abbate, C. 1993. 'Opera; or, the envoicing of women' in Musicology and difference: gender and sexuality in music scholarship ed. R. A. Solie, Berkeley/Los Angeles: University of California Press, pp. 225-58.

---. 2004. 'Music - Drastic or Gnostic?' in Critical Inquiry 30/3, pp. 505-36.

Barthes, R. 1977. 'The grain of the voice' in Image Music Text: Essays selected and translated by Stephen Heath. London: Fontana Press, pp. 179-89.

Bibby, M. 2007. 'Atrocity exhibitions: Joy Division, Factory Records, and goth' in Goth: Undead Subculture, ed. L. M. E. Goodlad and M. Bibby, Durham/London: Duke University Press, pp. 233-56.

Blesser, B. and Salter, L. 2007. Spaces Speak, Are You Listening? Experiencing Aural Architecture. Cambridge, MA: The MIT Press.

Bonenfant, Y. 2010. 'Queer listening to queer vocal timbres' in Performance Research, 15/3, pp. $74-80$.

Camilleri, L. 2010. 'Shaping sounds, shaping spaces' in Popular Music 29/2, pp. 199-211.

Carpenter, A. 2012. 'The "ground zero" of goth: Bauhaus, "Bela Lugosi's Dead" and the origins of gothic rock' in Popular Music and Society 35/1, pp. 25-52.

Dolar, M. 2006. A Voice and Nothing More. Cambridge, MA: MIT Press.

Eidsheim, N. S. 2014. 'Race and the aesthetics of vocal timbre' in Rethinking Difference in Music Scholarship, ed. O. Bloechl, M. Lowe and J. Kallberg, Cambridge: Cambridge University Press, pp. 338-65.

Goehr, L. 1998. The Quest for Voice: Music, Politics, and the Limits of Philosophy. Oxford: Oxford University Press.

Gunn, J. 1999 'Gothic music and the inevitability of genre' in Popular Music and Society 23/1, pp. 31-50.

Hodkinson, P. 2002. Goth: Identity, Style and Subculture. Oxford: Berg.

Ihde, D. 2007. Listening and Voice: Phenomenologies of Sound. Albany: SUNY.

Moore, A.F. 2012. Song Means: Analysing and Interpreting Recorded Popular Song (Farnham: Ashgate)

Omnia http://www.worldofomnia.com/. Accessed 20 April 2016

Shaviro, S. 2006. 'A voice and nothing more', http://www.shaviro.com/Blog/?p=489 Accessed 22 April 2016.

Sopor Aeternus and the Ensemble of Shadows http://www.soporaeternus.de/ Accessed 24 April 2016.

Tagg, P. 2013. Music's Meanings: A Modern Musicology for Non-Musos (New York and Huddersfield: The Mass Media Music Scholars' Press)

Van Elferen, I. 2012. Gothic Music: The Sounds of the Uncanny. Cardiff: Wales University Press.

--- and J. A. Weinstock. 2015. Goth Music: From Sound to Subculture. New York: Routledge.

Veil of Light http://veiloflight.bandcamp.com/album/-. Accessed 16 April 2016

Walser, R. 1993. Running with the Devil: Power, Gender, and Madness in Heavy Metal Music. Hanover, NH: University Press of New England.

Zagorski-Thomas, S. 2014. The Musicology of Record Production. United Kingdom: Cambridge University Press.

Zak, A. J. III. 2001. The Poetics of Rock: Cutting Tracks, Making Records. Berkeley: University of California Press.

\section{Discography}


Pre-publication manuscript. Article accepted for Popular Music (2017 issue). Do not quote before publication.

Sopor Aeternus and the Ensemble of Shadows, 'Dreamland', Poetica. Apocalyptic Vision, AV-030-CD. 2013.

Veil of Light, 'Cold skin', Cold Skin, Edition Gris ED|GR, 7" Vinyl and Digital. 2013. 
Pre-publication manuscript. Article accepted for Popular Music (2017 issue). Do not quote before publication.

\section{Notes}

${ }^{1}$ Some applications of this methodology such as the unfortunate comparisons of vocal chords with female organs, on the other hand, illustrate the risks of over-stating the importance of embodiment in music (Middleton 2006: 93-8).

${ }^{2}$ Bitonality is not unusual in goth music. Bauhaus's 'Bela Lugosi's Dead,' for instance, is musically un/located between B minor and E minor (Carpenter 2012: 35). 